\title{
Nuclear Medicine Advanced Associates: Physician Extenders in Nuclear Medicine-Now Is the Time
}

\author{
Mary Anne Owen ${ }^{1,2}$, Katie Neal Sinotte ${ }^{3}$, Norman Bolus ${ }^{1,4}$, Richard Siska ${ }^{1,5}$, Justin Jacob ${ }^{1,6}$, Vicki LaRue ${ }^{1,7}$, \\ Blaine Norton $^{1,8}$, and Darko Pucar ${ }^{1,9}$ \\ ${ }^{I}$ SNMMI Advanced Associate Council, Reston, Virginia; ${ }^{2}$ Augusta University, Augusta, Georgia; ${ }^{3}$ Nuclear Medicine Technology \\ Certification Board, Atlanta, Georgia; ${ }^{4}$ UAB School of Health Professions, Birmingham, Alabama; ${ }^{5}$ Mercy Imaging Services, Rolla \\ and Lebanon, Missouri; ${ }^{6}$ Molecular Imaging and Therapy Service, Memorial Sloan Kettering Cancer Center, New York, New York; \\ ${ }^{7}$ Institute for Advanced Biomedical Imaging, National Jewish Health, Denver, Colorado; ${ }^{8}$ Numed, Inc., Crossroads, Texas; and ${ }^{9}$ Yale \\ University School of Medicine, New Haven, Connecticut
}

From its inception in 2008 until 2020, the nuclear medicine advanced associate (NMAA) has evolved into a valuable member of the imaging team. Data show that NMAAs perform key services including supervision, interpretation, protocoling of adjunct studies, and management, freeing nuclear medicine physicians to concentrate on more complicated and timeintensive responsibilities. Additionally, the profession has gained ground by becoming recognized by the Nuclear Medicine Technology Certification Board (NMTCB), with the advent of a formal NMAA certification examination and recognition guidelines for institutions interested in establishing NMAA educational programs. Actions are under way for the creation of new NMAA programs with pathways to enhance and expand student recruitment. A special task force has been established by the Society of Nuclear Medicine and Molecular Imaging Advanced Associate Council to raise awareness of the advantages of the physician extender within the practice setting. Practicing NMAAs perform duties that are beyond the scope of nuclear medicine technologists.

Key Words: nuclear medicine advanced associate; NMAA; nuclear medicine technology certification board; NMTCB; nuclear medicine education

J Nucl Med Technol 2020; 48:241-245

DOI: $10.2967 /$ jnmt.120.242362

\section{$\mathbf{M}$}

ultilevel health care is rapidly becoming a standard operating mode in most clinical specialties. Providers such as nurse practitioners and physician assistants are working along with physicians across the country providing midlevel care, allowing physicians to be more productive and focused on high-level care. The transition to multilevel care has been slower in imaging specialties, particularly in nu-

\footnotetext{
Received Jan. 17, 2020; revision accepted Mar. 28, 2020.

For correspondence and reprints contact: Mary Anne Owen, Augusta University, College of Allied Health Sciences, 987 St. Sebastian Way, Augusta, GA 30912.

E-mail: mowen@augusta.edu

Published online Apr. 20, 2020.

COPYRIGHT @ 2020 by the Society of Nuclear Medicine and Molecular Imaging.
}

clear medicine. However, because the volume and complexity of nuclear medicine diagnostic and therapeutic procedures are increasing, it is easy to foresee that midlevel providers will be essential for the future of nuclear medicine. To facilitate transitioning of nuclear medicine to multilevel care, it is important to advance the opportunities for training and employment of mid-level providers in nuclear medicine.

Within the Society of Nuclear Medicine and Molecular Imaging (SNMMI), the Advanced Associate Council (AAC) has been a primary advocate for mid-level providers in nuclear medicine, focusing on training, practice, and job opportunities. At the 2018 midwinter meeting in Orlando, the SNMMI board of directors accepted the AAC proposal and endorsed the nuclear medicine advanced associate (NMAA) as fulfilling the physician extender role in nuclear medicine. The first NMAA class graduated in 2010. Since that time, 16 NMAAs have been credentialed by the Nuclear Medicine Technology Certification Board (NMTCB). NMAAs are evolving into a vital arm of nuclear medicine practice. NMAAs currently work in varying capacities within general nuclear medicine, nuclear cardiology, PET/CT, and radionuclide therapy. The needs of the workplace have defined how and where they practice. NMAAs, by virtue of their training as nuclear medicine technologists (NMTs) and mid-level providers, have been extremely flexible in meeting practice needs.

\section{NMAA EDUCATION}

The initial NMAA training program was established as a consortium at the University of Arkansas for Medical Sciences, St. Louis University, the University of Missouri, and, later, the Medical College of Georgia and was operational from 2008 to 2018. The program closed for several institutional reasons, but the 16 graduates continue to work as intended in a variety of nuclear medicine practice settings.

Though their numbers are few and no training program currently exists, new efforts to bring on a resurgence are under way by the SNMMI AAC. Physician assistant programs took 15-20 y to achieve wide acceptance within 
health care, starting in the early 1960s and not really gaining broad acceptance until the early 1980s. A shortage of physicians was the impetus behind the branding of the physician assistant. Implementation has proven that physician assistants provide a much-needed, cost-effective expansion of providers, especially in rural and underserved settings (1). The decline in dedicated nuclear medicine and molecular imaging physicians emphasizes the need for the same options to maintain and grow the ever-expanding nuclear market.

\section{EDUCATIONAL RECOGNITION}

In addition to the establishment of a standardized credentialing examination, in recent years the SNMMI AAC has worked closely with the NMTCB to create a robust pathway for the regeneration of the NMAA career. To this end, the NMTCB distributed - among the SNMMI board, AAC, and leadership - a position paper supporting the NMAA (personal communication, NMTCB, November 2016). The NMTCB believes that the NMAA is an important addition to the nuclear medicine field and will continue to grow as other physician extenders have in parallel fields. The NMTCB also believes that these advanced technologists will need the validity and quality of certification and recertification that the NMTCB can provide. The NMTCB will continue to support the NMAA certification program and NMAA certificants. By continuing on this course, the NMTCB's intent is to help spur recognition of the NMAA in those states that already use the NMTCB certification in order to create a gold standard for legitimization in other areas of nuclear medicine and to promote unparalleled quality in the nuclear medicine arena.

One change from previous NMAA program requirements is elimination of the requirement for NMAA applicants to be practicing NMTs. This factor greatly limited those who might be interested in admission to NMAA programs and restricted recruitment. New guidelines allow for training at the master's-degree level for new NMT grads, who will receive a greater number of NMAA clinical hours, similar to the number required for medical residency training. Proposed training extends the amount of training previously offered under the University of Arkansas consortium NMAA program.

Additionally, to encourage and support the creation of new NMAA educational programs, the NMTCB worked with the SNMMI AAC to create program recognition guidelines that provide interested institutions with a framework for establishing new programs (Table 1) (2). These guidelines include recommendations for content, admissions standards, format, location, program resources, and clinical standards.

\section{NEW NMAA PROGRAM INITIATIVE}

There is a new NMAA program in the early stage of development at the University of Alabama at Birmingham. Currently in the formative stages of the approval process is a proposed graduate-track option to go along with the master of science in nuclear medicine technology entry- level program. This track would allow graduates of the University of Alabama at Birmingham master of science in nuclear medicine technology program an avenue for advanced practice as a NMAA. The hope and expectation are that a program can be designed in a way that allows bachelor of science-educated students to take advantage of this track and be able to apply to the program. Because it is in the early stages, full details are not yet available. Faculty at the University of Alabama at Birmingham are aiming for a fall 2021 start, but this could be delayed. Unfortunately, because of the way academia works, it takes time to bring new programs, tracks, and offerings to fruition. Signs are hopeful at this time.

\section{NMAA PRACTICE SURVEY}

To better understand the opportunities and challenges of NMAA practice, the AAC recently conducted a survey. Although the number of survey recipients was small (16 total), all responded to the survey. The results provide some quantitative data revealing just how the NMAAs practice within today's busy imaging professions, including areas beyond the scope of the NMT, and are helpful for future planning. Thirty-three percent of the respondents supervise 16 to more than 20 nuclear medicine procedures per week, and $25 \%$ supervise 1-10 nuclear medicine procedures per week; $25 \%$ provide preliminary interpretation of nuclear medicine procedure results; $19 \%$ provide supervision of 16 to more than $20 \mathrm{PET} / \mathrm{CT}$ procedures per week; $13 \%$ provide preliminary interpretation of PET/CT results; $19 \%$ provide supervision of 16 to more than 20 nuclear cardiology procedures per week, and $25 \%$ supervise $1-10$ nuclear cardiology procedures per week; $31 \%$ provide preliminary interpretation of nuclear cardiology procedure results; 38\% supervise 1-10 lymphoscintigraphy cases per week; $25 \%$ supervise $1-10{ }^{131}$ I therapy cases per week; and $25 \%$ supervise $1-5$ parenteral nuclear medicine therapy cases per week.

\section{NMAA PRACTICE}

The data from the practice survey clearly show that NMAAs are involved in all aspects of nuclear medicine and molecular imaging practice, including supervision, and, to a lesser extent, preliminary interpretation. Although this information is useful, it reveals only a few quantitative aspects of NMAA practice. The NMAAs also provided some qualitative analysis that shows the broad effect they have on the quality of daily nuclear medicine operations. It is in these pearls that the real value of the NMAA is revealed.

As indicated by the practice survey, NMAAs are performing advanced duties within clinical practice settings that include, but are not limited to, supervising and interpreting studies. This is only one indication of how their careers have lent value to today's imaging environment. In a qualitative response, NMAAs reported a wide variety of expanded duties resulting from their formal didactic education 


\begin{tabular}{|c|c|}
\hline Parameter & Guideline \\
\hline Program location & $\begin{array}{l}\text { Sponsoring institution of NMAA program must be accredited by recognized regional, national, or } \\
\text { state agency and be legally authorized to provide program of postsecondary education; all } \\
\text { academic affiliates must be accredited by recognized regional, national, or state agency }\end{array}$ \\
\hline Program responsibilities & $\begin{array}{l}\text { Program is responsible for establishing admissions criteria and curricular plan; maintaining } \\
\text { and documenting effective supervision, coordination, and continuing communication with } \\
\text { all affiliated academic and clinical institutions to ensure that students receive equivalent } \\
\text { and adequate instruction and clinical experiences; initiating formal affiliation agreement } \\
\text { whenever another institution provides academic or clinical education to students as part } \\
\text { of a professional program; and ensuring that activities assigned to students in a clinical } \\
\text { setting are educational }\end{array}$ \\
\hline Program personnel & $\begin{array}{l}\text { Sponsoring institution must provide or ensure that there is sufficient administrative, instructional, } \\
\text { and support personnel for curriculum and program enrollment; program's personnel include, but } \\
\text { are not limited to, program director, medical advisor, instructional faculty, and staff support }\end{array}$ \\
\hline Program resources & $\begin{array}{l}\text { Sponsor's human, physical, financial, and learning resources must be sufficient to support educational } \\
\text { goals and number of students admitted into program }\end{array}$ \\
\hline Clinical affiliation sites & $\begin{array}{l}\text { All clinical affiliation sites must be accredited by American College of Radiology, Intersocietal } \\
\text { Accreditation Commission, or the Joint Commission }\end{array}$ \\
\hline Clinical curriculum & $\begin{array}{l}\text { Clinical component of program must provide an environment for supervised, competency-based } \\
\text { clinical education and offer a sufficient and well-balanced variety of nuclear medicine procedures }\end{array}$ \\
\hline
\end{tabular}

Full educational program guidelines are available online (2).

and clinical internships. The NMAA internships included experience under the supervision of physicians in cardiac, general nuclear medicine, therapeutic, and PET settings. NMAAs were mentored by physician preceptors in all aspects of medical management. The experience was similar to that of medical residents. Since graduating and entering NMAA careers, they have reported evolving into a wide variety of responsibilities, many carved out by the needs of their individual practice settings.

In a separate anecdotal polling, NMAAs were asked to describe their daily practice activities that they felt entered into advanced practice. In actual NMAA practice, many of the responsibilities reported by NMAAs are differentiated from the responsibilities of NMTs and fall into the realm of what are traditionally considered physician duties. For example, they...

- Dictate preliminary findings on all general nuclear medicine, nuclear cardiology, and PET/CT examinations. As is done for any mid-level provider, these findings are then over-read by the attending radiologist for the final interpretation and signing. (Per Vicki LaRue at Jewish Health in Denver: "At last count, I touch $90 \%$ of all [nuclear medicine] studies before final sign-off by radiologists. Half of my workday (sometimes more) is dedicated to reading.")

- Contact ordering physicians with critical findings. (This is required per the attending radiologist and then dictated into the report.)

- Protocol all nuclear medicine studies, applying appropriate-use criteria (prescribing doses and images for clinical studies); verify the clinical correlation and relevance by ordering adjunct imaging studies and labo- ratory tests; and contact ordering physicians to suggest appropriate changes.

- Perform clinical workup for nuclear medicine diagnostic or therapeutic procedures, including administering medications that are not within the scope of technologists, reviewing medication lists and answering any patient questions, and serving as the direct contact for any technologist questions (e.g., approving studies such as ventilation-perfusion scans for determining the probability of pulmonary embolism, approving potential stress-only myocardial perfusion imaging, and checking for myocardial suppression in evaluation of cardiac sarcoidosis causing abnormal tracer distribution in order to determine if the patient has been compliant with procedure preparation). Delegating these responsibilities to a specialized nuclear medicine physician extender allows radiologists to focus on complex cases, oversee invasive procedures, consult with referring physicians, and prepare for case conferences. - Interpret dual-energy x-ray absorptiometry studies.

- Create access for hepatic arterial infusion pumps.

- Engage in a theranostics role, such as performing patient consultations and assessments before and after treatment with such agents as ${ }^{177}$ Lu-DOTATATE (Lutathera; Advanced Accelerator Applications) and ${ }^{223}$ Ra-dichloride (Xofigo; Bayer) (physical examinations, overview of laboratory testing, pre-dictations for the attending physician) and helping the authorized user with therapy infusions.

- Supervise stress tests, including providing a preliminary report and, if there is a patient emergency, quickly triaging, stabilizing the patient, and collaborating with the supervising physician. 
- Make injections for sentinel node mapping for surgeons.

- Ensure compliance with Nuclear Regulatory Commission regulations and supervise new-department openings.

- Serve as the regional manager for a nuclear firm.

Furthermore, NMAAs have moved into directorships and supervisory positions previously reserved for nurse practitioners and physician assistants. The comprehensive educational content in health-care management that is part of the NMAA curriculum has prepared graduates to manage practices using evidence-based data and to apply medical informatics. These areas are not currently the purview of NMT educational programs.

\section{NMAA JOB RECOGNITION}

For NMAAs to fully benefit from their advanced training and optimally contribute to health care, official NMAA job recognition by key stakeholders at the national level will ultimately be necessary. The AAC is forming a task force to organize this effort. In 2019, the roles and responsibilities of NMAAs were accepted and approved by a resolution of the American College of Radiology (3) and the SNMMI. In the beginning of 2019, NMAAs collectively made a case to the Nuclear Regulatory Commission to be recognized as authorized users, albeit in a limited scope. Although their case was compelling, the Nuclear Regulatory Commission was not ready to proceed. During that time, the AAC began working with an experienced medical-imaging lobbyist. It was believed that the NMAA might achieve recognition as part of the Medicare Access to Radiology Care Act bill. The American Society of Radiologic Technologists and the American Registry of Radiologic Technologists had been lobbying for the radiologist assistant to receive Medicare reimbursement for certain examinations and recently had experienced some success. The NMAA language was crafted to focus not on reimbursement but on recognition, for which it was believed that adoption and acceptance would be easier, given the low volume of practicing NMAAs. The American Society of Radiologic Technologists and the American Registry of Radiologic Technologists had invested great time and money into their lobbying effort, but because of the delicate nature of this endeavor for radiologist assistants and the difficulty of advancing the bill, the 2 organizations did not feel it prudent to insert any new language in the bill at that time. The AAC did honor their request to not insert any new language into the Medicare Access to Radiology Care Act bill and expressed its support for the radiologist assistant. The Medicare Access to Radiology Care Act bill has since been stalled in legislature because of other high-profile, time-consuming issues. One idea for additional lobbying efforts was to try to insert the NMAA through the Veterans Affairs (VA) system. The VA is actively looking for cost-effective ways to improve treatment for those that they serve, and for new ways to take advantage of their recent expansion of the radiology assistants. One suggested approach was to first nationally seek and obtain any approvals or guidelines that may be necessary to enable the individual VA hospitals to utilize NMAAs. Another approach was to target individual VA hospitals to get the administration and departments to accept and adopt policies and hire NMAAs. In some cases, that may be relatively simple, particularly if the physicians and other practitioners are familiar with NMAAs and can make it happen. We would need to identify a few potential hospitals where we could try to implement this quickly, which could enable us to use that success as a springboard to drive adoption elsewhere. This would be driven at least initially by the SNMMI / SNMMI-TS identifying members within the VA system who would help push the policy. There was a policy shift by the SNMMI Technologist Section and the American Society of Radiologic Technologists from pushing a national licensure for technologists to focusing on state licensure. Initiatives similarly are under way within the AAC, such as the targeting of states with NMAAs for a push for their advanced licensure.

\section{OBSTACLES}

Although the NMAA initiative has a positive and encouraging outlook, it depends on several factors that may limit forward movement. The major factor is the ability to ensure implementation of a new program, such as that under development at the University of Alabama at Birmingham. Additionally, adequate marketing to program directors, students enrolled in NMT educational programs, and interested working NMTs is necessary to stimulate recruitment and enrollment in new programs. Also, support from the SNMMI and the medical community is needed to promote the value of the NMAA within the practice setting. Greater efforts toward increasing the visibility of the NMAA are imperative to move the profession forward.

\section{CONCLUSION}

The NMAA initiative is alive, well, and moving forward. NMAAs are now SNMMI-recognized physician extenders in nuclear medicine, with diverse, flexible, and effective roles in nuclear medicine diagnostic and therapeutic procedures and nuclear medicine management. Efforts to create robust education and employment opportunities are under way. Interested readers who wish to become involved in the exciting future of the AAC and the NMTCB are encouraged to make inquiries of any of the following leaders in the field: Darko Pucar, MD, PhD, president of the AAC, (darko1pucar@outlook.com); Mimi Owen, MHE, $\operatorname{ARRT}(\mathrm{N})$, interim vice president of the AAC (mowen@ augusta.edu); Richard Siska, NMAA, job recognition task force of the AAC (ricksiska@ hotmail.com); and Katie Neal 
Sinotte, executive director of the NMTCB (kneal@nmtcb.org). In addition, the fall 2019 newsletter of the AAC can be found on its website (https://www.snmmi.org/AboutSNMMI/Council. aspx?ItemNumber $=6562$ ).

\section{DISCLOSURE}

No potential conflict of interest relevant to this article was reported.

\section{REFERENCES}

1. History of the PA profession. American Academy of PA website. https://www. aapa.org/about/history/. Accessed May 12, 2020.

2. Nuclear medicine advanced associate educational program recognition guidelines. Nuclear Medicine Technology Certification Board website. http://www.nmtcb.org/ documents/NMAA-Educational-Program-Recognition-Guidelines-Final-2019.pdf. Accessed May 12, 2020.

3. Digest of council actions: 2019-2020. American College of Radiology website. https://www.acr.org/-/media/ACR/Files/Governance/Digest-of-Council-Actions.pdf. Accessed May 12, 2020. 